\title{
Long-term climatic trend analysis of Giridih district, Jharkhand (India) using statistical approach
}

\author{
Mukesh Kumar $^{1}$ - D. M. Denis ${ }^{1} \cdot$ Shakti Suryavanshi $^{2}$
}

Received: 7 May 2016/Accepted: 4 June 2016/Published online: 22 June 2016

(C) Springer International Publishing Switzerland 2016

\begin{abstract}
The present study has been carried out for longterm trend analyses of past climatic variables using nonparametric tests (MK test, sequential Mann-Kendall and Theil-Sen's slope) for the Giridih district in Jharkhand (India). In addition, sequential Mann-Kendall test were used to see change with time. However, in the serially correlated series, pre-whitening has been used before employing the MK test. The long-term trend analysis based on meteorological station to exhibit a trend in annual and seasonal precipitation for the study area. It was found that there was no significant trend observed in monsoon and summer session for maximum and minimum temperature. Whereas, a significant increasing trend in the region was observed for the winter season. Hence, rainfall is concerned; there was a significant decreasing trend of $2.04 \mathrm{~mm} /$ year observed during the monsoon season. There were good agreements with all climatic variables corresponding to the statistical analysis.
\end{abstract}

Keywords Trend analysis $\cdot$ Mann-Kendall $\cdot$ Climatic phenomenon $\cdot$ Pre-whitening test

Mukesh Kumar

mukesh_fo@yahoo.co.in

1 Department of Soil Water Land Engineering and Management, Sam Higginbottom Institute of Agriculture, Technology and Sciences, Allahabad, Uttar Pradesh, India

2 Shepherd School of Engineering and Technology, Sam Higginbottom Institute of Agriculture, Technology and Sciences, Allahabad, Uttar Pradesh, India

\section{Introduction}

Statistical analysis has received greater attention for hydrometeorological studies in order to investigate climate change scenarios from the scientific community. According to Intergovernmental Panel on Climate Change report (IPCC 2007), anthropogenic emission of various gases has increased considerably since industrialization have caused the planet to warm by about $1{ }^{\circ} \mathrm{C}$. This, change in temperature may influence long-term rainfall patterns impacting the availability of water, which is a major global environmental issues in recent time (Barnett et al. 2005). Magnitude and trend of warming of India during the last century is matching with the global condition (Pant and Kumar 1997). Change in climate over the India by southwest monsoon causes drastic change in hydrological parameters such as precipitation, evaporation and streamflow, would have a significant impact of agricultural production, water resources management and overall economy of the country (Dvorak et al. 1997; Lal 2001; Eckhardt and Ulbrich 2003; Gosain et al. 2006; Jiang et al. 2007; IPCC 2007; Kalra et al. 2008; Jain and Kumar 2012; Sonali and Kumar 2013). Therefore, trend analysis of long-term hydrologic, as well as climatic data has been extensively used to assess the potential impacts of climatic change and variability $(\mathrm{Ru}-$ pakumar and Hingane 1988; Rao and Kumar 1992; Chen et al. 1992; Hingane 1995; Pant and Kumar 1997; Kadioglu 1997; Sadhukhan et al. 2000; Lu et al. 2004; Arora et al. 2005; Gadgil and Dhorde 2005; Tomozeiu et al. 2006; Singh et al. 2008; Subash et al. 2011; Jain and Kumar 2012; Suryavanshi et al. 2014; Kishore et al. 2016).

Trend analysis of long-term time series consists of the magnitude of trend and its statistical significance. In general, trend detection studies for different hydrologic and climatic variables is determined either using parametric test or nonparametric methods (Sen 1968, Reeves et al. 2007, Khaliq et al. 
2009). Sen's non-parametric estimator of slope has been frequently used to estimate the magnitude of trend, whose statistical significance was assessed by the Mann-Kendall test.

In this study, the variability of the climatic parameters of the Giridih district of Jharkhand, India has been studied by non-parametric test for detecting trend in the time series is Mann-Kendall (MK) test (Mann 1945; Kendall 1975). Previous studies have exhibited the significant decreasing rainfall trends in the monsoon season, whereas during December, significant increasing trend of rainfall have been observed in Jharkhand (Rajeevan et al. 2006; Guhathakurta and Rajeevan 2008). In addition, as per the JSAC (2010) report of Giridih has been identifed as one of the district which consists of Chirki, Irgo, Usri and Jamunia watersheds came under either high priority for development and management. The district has been identified as highly undeveloped due to lack of irrigation facility, the main stay of the people of the area is agriculture. Therefore, information on climatic parameters of the area at the local scale is of utmost important for the planning and development. The present study aims at analyzing persistence and trend of various climatic parameters such as rainfall, minimum, maximum temperature and evapo-transpiration of the Giridih district. Rather than, this study could serve as a base land for preparing of sustainable water resource development and management planning for the undeveloped district like Giridih which is having full of natural resources.

\section{Study area}

Giridih (Jharkhand) is located in central north east India and geographical extension is $24^{\circ} 10^{\prime} \mathrm{N} 86^{\circ} 21^{\prime} \mathrm{E}$ (Fig. 1). The Giridih district has three types of topographical areas viz. central plateau having moderate elevation, lower plateau having lower elevation and the trough basin of Damodar consist of 4853.56 sq. km. The area is drained by river Barakar, Sakri and Usri. The climate of Giridih is generally dry. The district receives average annual rainfall of $1137 \mathrm{~mm}$. (2004-2008) and most of the rainfall occurs during the rainy season. The daily mean temperature ranges from a maximum of $47{ }^{\circ} \mathrm{C}$ to a minimum of $10{ }^{\circ} \mathrm{C}$. District consists of vast forest which is uniformly distributed. The district is rich in mineral recourses and it has several large coal fields which contents one of the best qualities of metallurgical coal in India.

\section{Data used}

To study the temporal changes in climate of the Giridih district, a trend analysis of the following climatic variables were considered: (1) annual and seasonal rainfall, (2) seasonal minimum and maximum temperature and (3) seasonal and annual potential evapo-transpiration (PET). The data were obtained for 102 years (1901-2002) from India water portal (www.indiawaterportal.org). For seasonal analysis, the water year (i.e., 1 June-31 May) was classified into three seasons, each of 4 months duration. Season 1 corresponds to the monsoon season (June-September); season 2 corresponds to the winter season (October-January), and season 3 corresponds to the summer season (February-May).

\section{Methodology}

The methodology used for evaluation of trends in hydrological variables for individual station is carried out using the MannKendall non- parametric trend test (Mann 1945; Kendall 1975). The following steps have been involved in this study: (i) test the serially correlated or serial-correlated effects of observed climatic data; (ii) If positive serial correlation (persistence) is present in the climatic data, was removed by pre-whitening; (iii) Applying the Mann-Kendall test; (iv) Applying the sequential Mann-Kendall test; (v) Applying Sen's T test.

\section{Persistence}

Persistence is evident in long series of climatic observations characterized by a positive serial correlation. In hydrological time series studies, the series is called persistence if the data in the series are dependent on each other. Persistence is also referred to serial correlation or serial correlation. Practically persistence is a tendency for successive values of the climatologically time series to "remember" their antecedent values, and to be influenced by them (WMO 1966; Matalas 1967). Problem in detecting and interpreting trends in certain hydrological time series may frequently display statistically significant serial correlation. In case of presence of serial correlation in the hydrological time series increase the probability that the non parametric test will detects the significant trend (Kulkarni and Von Storch 1995). However, this approach has been widely used in several earlier works related to long-term climatic variation (Rodhe and Virji 1976; Nicholson and Palao 1993; Türkes et al. 2002; Partal and Kahya 2006; Hamed 2009; Suryavanshi et al. 2014; Kundu et al. 2014, 2015). To test the persistence in the climatologically time series, normalized anomaly of the time series are used. A normalized series is obtained as follows:

$X_{t}=\left(x_{t}-\bar{x}\right) / \sigma$

where, $X_{t}$ is the normalized anomaly of the series, $x_{t}$ is the observed time series, $\bar{x}$ and $\sigma$ are the long-term mean and standard deviation of annual/seasonal time series. All serial correlation coefficients of normalized climatic series are computed for lags $L=0$ to $m$, where $m$ is the maximum lag (i.e. $=n / 3) ; n$ is the length of the series. The serial correlation coefficient was computed from Eq. 2. 
Fig. 1 Study area

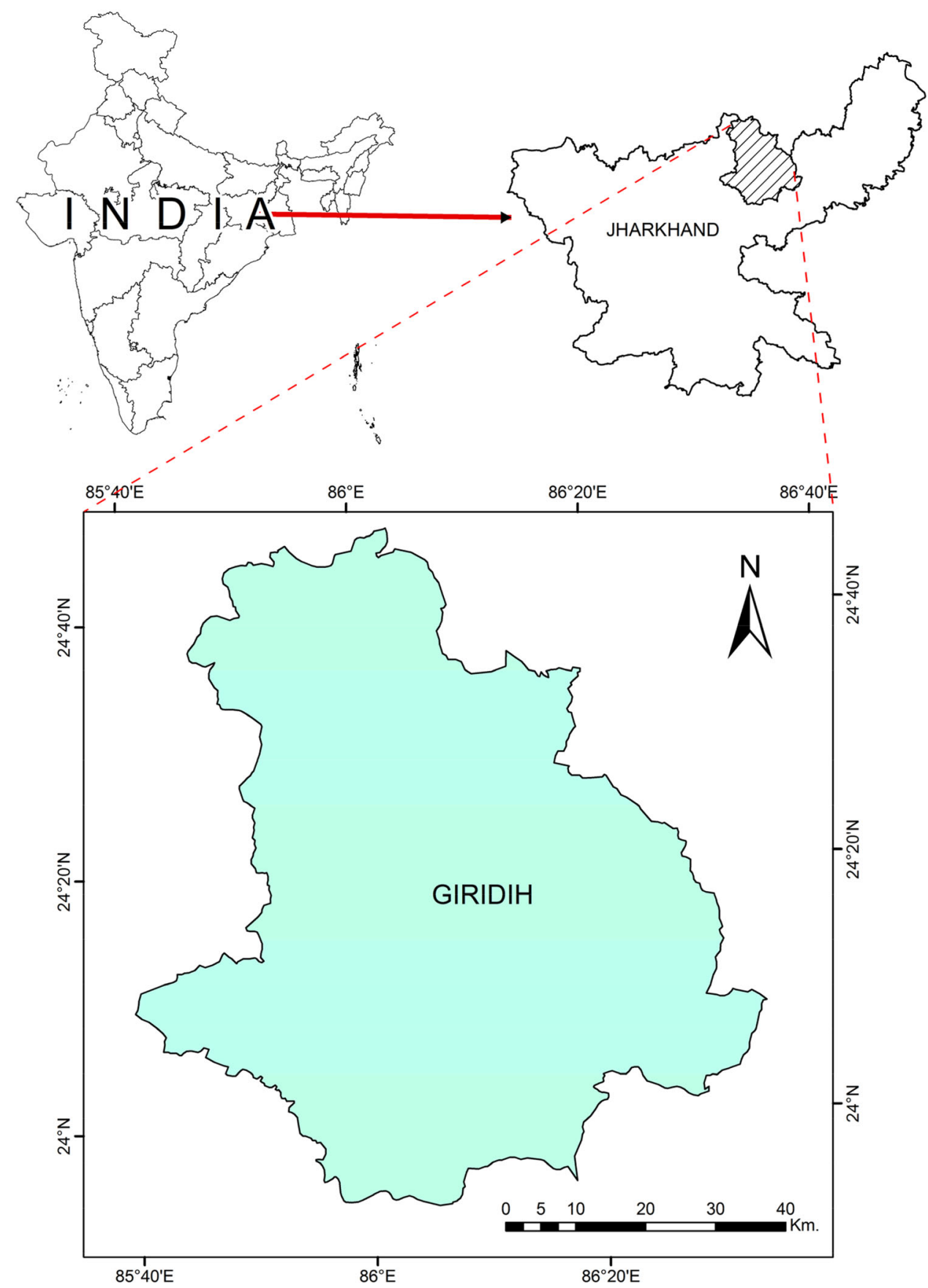

$r_{L}=\frac{\sum_{t=1}^{n-L}\left(X_{t}-\bar{X}_{t}\right) \cdot\left(X_{t+L}-\bar{X}_{t+L}\right)}{\left[\sum_{t=1}^{n-L}\left(X_{t}-\bar{X}_{t}\right)^{2} \cdot \sum_{t=1}^{n-L}\left(X_{t+L}-\bar{X}_{t+L}\right)^{2}\right]^{1 / 2}}$

To test the significance of serial correlation, Eq. (3) is used (Yevjevich 1971).

$r_{k}=\frac{-1 \pm t_{g}(n-k-1)^{1 / 2}}{n-k}$

where, $t_{g}=1.645,1.965,2.326$ are at 90,95 and $99 \%$ confidence interval respectively. The 'null' hypothesis of the randomness of climatic series against the serial correlation is rejected for the large value of $r_{1}$. If $r_{1}$ does not significantly differ from zero, then series is regarded to be free from persistence. In this case, the appropriate null continuum is termed as 'white noise'. However, in the study serial correlation coefficients up to $\operatorname{lag}^{3}$ were assessed (Basistha et al. 2009).

\section{Pre-whitening}

The term "pre- Whitening" was first proposed by Kulkarni and von Storch (1995) in order to eliminate the effect of serial correlation before applying the Mann-Kendall test. If 
serial correlation exists in the time series data, it leads to a disproportionate rejection of the null hypothesis of no trend, when in fact the null hypothesis should be accepted. In this study, MK test with pre-whitening procedure proposed by Yue et al. (2002) has been used to detect a significant trend in a time series with significant serial correlation. Similar method has also been used by Suryavanshi et al. (2014). The different steps are carried out in the following manner.

Step 1 The slope $(\beta)$ of a trend in sample data is estimated using the approach proposed by Theil (1950a) and Sen (1968). The original sample data $X_{t}$ were unitized by dividing each of their values with the sample mean $E\left(X_{t}\right)$ prior to conducting the trend analysis (Yue et al. 2002). By this treatment, the mean of each data set is equal to one and the properties of the original sample data remain unchanged. If the slope is almost equal to zero, then it is not necessary to continue to conduct trend analysis. If it is differs from zero, then it is assumed to be linear, and the sample data are de-trended by

$X_{t}^{\prime}=X_{t}-T_{t}=X_{t}-\beta * t$

Step 2 The lag-1 serial correlation coefficient $\left(\mathrm{r}_{1}\right)$ of the detrended series $X_{t}$ is computed using Eq. (4). If $r_{1}$ is not significantly different from zero, the sample data are considered to be serially independent and the MK test is directly applied to the original sample data. Otherwise, it is considered to be serially correlated and AR (1) is removed from the $X_{t}^{\prime}$ by

$\mathrm{Y}_{\mathrm{t}}^{\prime}=\mathrm{X}_{\mathrm{t}}^{\prime}-\mathrm{r}_{1} \cdot \mathrm{X}_{\mathrm{t}-1}^{\prime}$

This pre-whitening procedure after de-trending the series is referred to as the trend-free pre whitening (TFPW) procedure. The residual series after applying the TFPW procedure should be an independent series.

Step 3 The identified trend $\left(\mathrm{T}_{\mathrm{t}}\right)$ and the residual $\mathrm{Y}_{t}^{\prime}$ are combined as:

$\mathrm{Y}_{\mathrm{t}}=\mathrm{Y}_{t}^{\prime}+\mathrm{T}_{\mathrm{t}}$

The blended series $\left(\mathrm{Y}_{\mathrm{t}}\right)$ just includes a trend and a noise and is no longer influenced by serial correlation. Then the MK test is applied to the blended series to assess the significance of the trend.

\section{The Mann-Kendall test}

The Mann-Kendall trend test is a rank correlated test between the rank of observation and there time order. This method has been widely used to test for randomness against trend detection in a time series in climatology and hydrology (Mann 1945 and Kendall 1975). This test is found to be an excellent tool for trend detection by other researchers in similar application (Hirsch et al. 1982; Burn and Hag Elnur 2002; Yue et al. 2002; Suryavanshi et al. 2014)
$\mathrm{S}=\sum_{\mathrm{i}=1}^{\mathrm{n}-1} \sum_{j=\mathrm{i}+1}^{\mathrm{n}} \mathrm{a}_{\mathrm{ij}}$

where,

$a_{i j}=\operatorname{sgn}\left(x_{j}-x_{i}\right)=\left\{\begin{array}{cc}1 & x_{j}<x_{i} \\ 0 & x_{j}=x_{i} \\ 1 & x_{j}>x_{i}\end{array}\right\}$

and $R_{i}$ and $R_{j}$ are the ranks of observations $x_{i}$ and $x_{j}$ of the time series, respectively.

It has been documented that when $n \geq 10$, the statistic $S$ is approximately normally distributed with the mean zero and a variance is

$\operatorname{VAR}(S)=\frac{\mathrm{n}(\mathrm{n}-1)(2 \mathrm{n}+5)-\sum_{\mathrm{i}=1}^{\mathrm{m}} \mathrm{t}_{\mathrm{i}}\left(\mathrm{t}_{\mathrm{i}}-1\right)\left(2 \mathrm{t}_{\mathrm{i}}+5\right)}{18}$

where $n$ is the number of data points, $m$ is the number of tied groups (a tied group is a set of sample data having the same value), and $t_{i}$ is the number of data points in the ith group. A very high positive value of $\mathrm{S}$ is an indicator of an increasing trend, and a very low negative value indicates a decreasing trend.

The standardized test statistic $\mathrm{Z}$ is computed as follows:

$\mathrm{Z}=\left\{\begin{array}{cc}\frac{\mathrm{S}-1}{\sqrt{\mathrm{VAR}(\mathrm{S})}} & \text { if } S>0 \\ 0 & \text { if } S=0 \\ \frac{\mathrm{S}+1}{\sqrt{\mathrm{VAR}(\mathrm{S})}} & \text { if } S<0\end{array}\right\}$

The null hypothesis, H0, meaning that no significant trend is present, is accepted if the test statistic $Z$ is not statistically significant, i.e. $-\mathrm{Z}_{\alpha / 2}<\mathrm{Z}<\mathrm{Z}_{\alpha / 2}$, where $\mathrm{Z}_{\alpha / 2}$ is the standard normal deviate. In this study, three different significance levels i.e. 1,5 and $10 \%$ is considered.

\section{Sequential Mann-Kendall test}

The purpose of conducting the sequential MK tests is to see how the trends fluctuated over the study period. This test is considers the relative values of all terms in the time series $\left(\mathrm{x}_{1}, \mathrm{x}_{2} \ldots \mathrm{x}_{\mathrm{n}}\right)$. Sequential value $\mathrm{u}(\mathrm{t})$ and $\mathrm{u}^{\prime}(\mathrm{t})$ from the analysis of MK Test were determined in order to see change of trend with time (Sneyers 1990; Partal and Kahya 2006).The Sequential Mann-Kendall test procedure suggested by Partal and Kahya (2006) is used in this study

The sequential value of the statistic $u(t)$ is calculated as $\mathrm{u}(\mathrm{t})=\mathrm{t}_{\mathrm{j}}-\mathrm{E}(\mathrm{t}) / \sqrt{ } \operatorname{var}\left(\mathrm{t}_{\mathrm{j}}\right)$

The magnitude of $\mathrm{x}_{\mathrm{j}}$ annual mean time series, $(j=1 \ldots n)$ are computed with $x_{i}(i=1 \ldots j-1)$. At each 
comparison, the number of cases $x_{j}>x_{i}$ is counted and denoted by $n_{j}$. the statistics $t$ is then given by equation

$\mathrm{tj}=\sum_{1}^{\mathrm{j}} \mathrm{t}$

Mean and variance of the test statistics are calculated using

$$
\begin{aligned}
& E(t)=n(n-1) / 4 \text { and } \\
& \operatorname{Var}\left(t_{j}\right)=[j(j-1)(2 j+5)] / 72
\end{aligned}
$$

In the same way the value of $\mathrm{u}^{\prime}(\mathrm{t})$ are computed backward from the end of the time series data.

\section{Sen's estimator}

The linear trend value represented by slope of the data set can be estimated by using non-parametric procedure developed by Theil (1950b, c, d) and Sen (1968). In this method, the slopes $\left(T_{i}\right)$ of all data pairs are first calculated by

$T_{i}=x_{j}-x_{k} / j-k \quad$ for $i=1,2 \ldots \ldots . N$

where $x_{j}$ and $x_{k}$ are data values at times $j$ and $k(j>k)$, respectively. The median of these $N$ values of $T_{i}$ is sen's estimator of slope which is calculated as

$\beta=\mathrm{T}_{\mathrm{N}+1 / 2} \quad$ if $\mathrm{N}$ is odd

$\beta=1 / 2\left(\mathrm{~T}_{\mathrm{N} / 2}+\mathrm{T}_{\mathrm{N}+2 / 2}\right)$ if $\mathrm{N}$ is even.

A positive value of $\beta$ indicates an upward trend and the negative value indicates a downward trend in the time series.

\section{Relative change}

To compute the relative change of different climatic parameters, the following equation was used (Some'e et al. 2012).

$R C=\frac{n * \beta}{|\mathrm{x}|} * 100$

where, $\mathrm{n}=$ length of trend period, $\beta=$ magnitude of the trend slope of the time series which is determined by Sen's median estimator, and $|\mathrm{x}|=$ absolute average value of the time series.

\section{Results and discussions}

\section{Trend analysis}

To study the temporal changes in climate of the Giridih district Jharkhand, trend analysis of seasonal and annual minimum and maximum temperature, seasonal and annual rainfall, seasonal and annual potential evapotranspiration (PET) climatic variables were considered. The climatic variables were tested for persistence. In case of station exhibiting significant persistence, pre whitening test is carried out prior to trend analysis to eliminate the effect of serial correlation. Trend analysis was carried out at 1,5 and $10 \%$ significance level.

\section{Maximum temperature}

The seasonal maximum temperature was analyzed for a period of 101 years (1901-2002). Lag 1 serial correlation coefficient, the MK $\mathrm{z}$ value and significant level of trends, slope, intersection and relative change is presented in Table 1 . The sequential values of the $u(t)$ and $u^{\prime}(t)$ statistics, derived from a progressive analysis of the MannKendall rank correlation, are depicted respectively by solid and dashed lines shown in the Fig. 2. Horizontal dashed lines correspond to confidence limits at the 1,5 and $10 \%$ significant level. The monsoon season (season 1) and summer season (season 3) did not exhibit any significant trend. However in winter season (season 2), a significant trend was observed. Rising trend of maximum temperature in winter season ultimately increase the mean heating of the atmosphere may cause cloud formation and eventually increases the rainfall activity. The increasing trend in the winter season reflects the poor crop production in the Rabi season. The results of the sequential MK test show that there is no significant trend detected in maximum temperature in season 1 and season 3, since the graphical representation $\mathrm{u}(\mathrm{t})$ and $\mathrm{u}^{\prime}(\mathrm{t})$ gives curve that does not point out intersection point or overlap several time. However in season 2, it is noted that graphical representation begins to diverge in the early 1905 s indicating the starting point of the trend. Regarding yearly maximum temperature it should also be noted that two functions begin to diverge in the late 1950s indicate the starting point of trend. Longterm trends may be identified in increasing mode commencing in the late 1950s till the rest of period.

\section{Minimum temperature}

The seasonal minimum temperature of station was analyzed for a period of (1901-2002). The Lag1 serial correlation coefficient, the $\mathrm{MKz}$ value and significant level of trend, slope, intercept and relative change values for station is presented in Table 2. For monsoon season (season 1) and summer session (season 3), station showed a significant persistence with no any trends. However in winter season (season 2), station showed significant persistence with increasing trends. Like the maximum temperature, the slope and relative values for the stations is quite low. Based 
Table 1 Serial correlation analysis for maximum temperature

\begin{tabular}{llclccc}
\hline Season & r1 & ZMK & Trend & Sen slope & Intercept & Relative change \\
\hline Season 1 & 0.0582 & -0.5002 & 0 & -0.001 & 31.653 & -0.3098 \\
Season 2 & 0.3725 & 3.5911 & 1 & 0.0078 & 15.9037 & 3.0562 \\
Season 3 & 0.1831 & 0.1619 & 0 & 0.0004 & 27.3423 & 0.1174 \\
Yearly & 0.281 & 2.475 & 1 & 0.0032 & 21.6838 & 1.0640 \\
\hline
\end{tabular}

Fig. 2 Sequential value of statistics $\mathrm{u}(\mathrm{t})(-)$ and $\mathrm{u}^{\prime}(\mathrm{t})(-)$ : seasonal and yearly maximum temperature from MK test for Giridih station
Table 2 Serial correlation analysis for minimum temperature
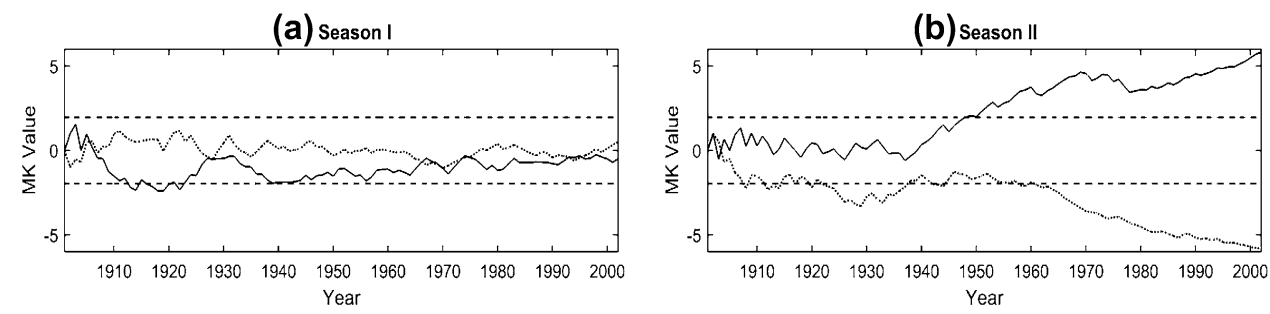

(c) Season III

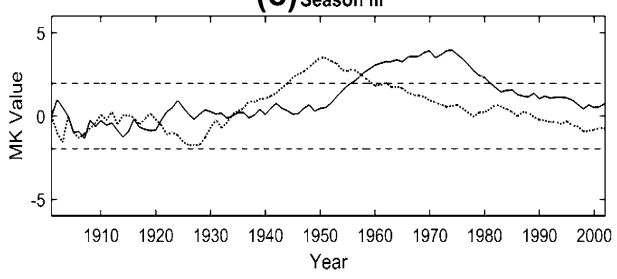

(d) Yearly

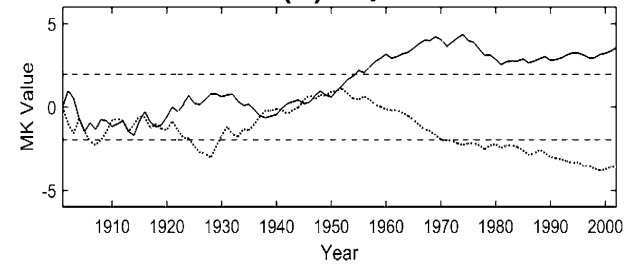

\begin{tabular}{lllclcl}
\hline Season & r1 & ZMK & Trend & Sen slope & Intercept & Relative change \\
\hline Season I & 0.3632 & 0.3874 & 0 & 0.0006 & 15.3507 & 0.2349 \\
Season II & 0.5226 & 2.8162 & 1 & 0.006 & 6.1041 & 4.5873 \\
Season III & 0.2121 & 1.1797 & 0 & 0.0024 & 14.924 & 1.2937 \\
Yearly & 0.5518 & 1.8042 & 10 & 0.0023 & 8.347 & 1.2708 \\
\hline
\end{tabular}

on the average value of MK test statistics, it was observed that no significant trend was observed in the monsoon season and summer season, whereas an increasing trend was observed in the winter season for minimum temperature. The results of the sequential MK test for minimum temperature have shown in Fig. 3. There was no significant trend detected in minimum temperature in season 1 and season3, since the graphical representation $\mathrm{u}(\mathrm{t})$ and $\mathrm{u}^{\prime}(\mathrm{t})$ gives curve that does not point out intersection point or overlap several time. However when inspecting the plot of $\mathrm{u}(\mathrm{t})$ and $\mathrm{u}^{\prime}(\mathrm{t})$ in season 2 , meaningful long term-trends may be identified in decreasing mode commencing in the early 1910s and ending in early 1930s, and immediately after in the increasing mode till early 1945s. It was also observed that decreasing mode of minimum temperature in season 2 again started in early 1980s for the rest of period.

\section{Potential evapo- transpiration (PET)}

The Lag1 serial correlation coefficient, the $\mathrm{MKz}$ value and significant level of trend, slope, intercept and relative change of annual and seasonal PET of 102 years was carried out and shown in Table 3. In case of all three season, a significant trend was observed. Season II and season III showed no any trend with very low value of slope, whereas season 1 exhibited a significant decreasing trend. The results of the sequential MK test for PET have been presented in Fig. 4. There is no significant trend detected in PET in season II and season III. However in season $\mathrm{I}$, it is noted that plot of $\mathrm{u}(\mathrm{t})$ and $\mathrm{u}^{\prime}(\mathrm{t})$ representation begins to diverge in the early 1990s indicating the starting point of the trend. PET does not showed any significant trend in winter however, increasing trend of winter minimum and maximum temperature was observed. This may be because of PET not only depends on the temperature, but also on other metrological variables such as wind speed, sunshine hour and solar radiation which are not considered in the present study.

\section{Rainfall}

Seasonal and yearly rainfall was analyzed for a period of (1901-2002). Lag1 serial correlation coefficient, the $\mathrm{MKz}$ value and significant level of trends, slope, intersection and 
Fig. 3 Sequential value of statistics $\mathrm{u}(\mathrm{t})(-)$ and $\mathrm{u}^{\prime}(\mathrm{t})(-)$ : seasonal and yearly minimum temperature from MK test for Giridih station

Table 3 Serial correlation analysis for PET (a) Season I

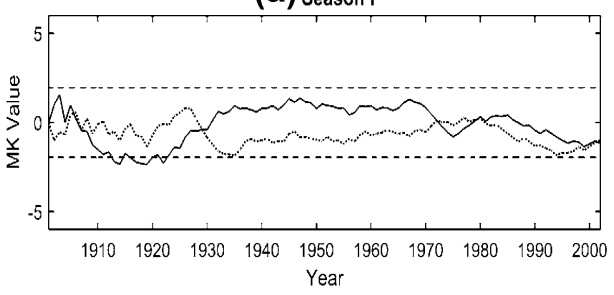

(c) Season II

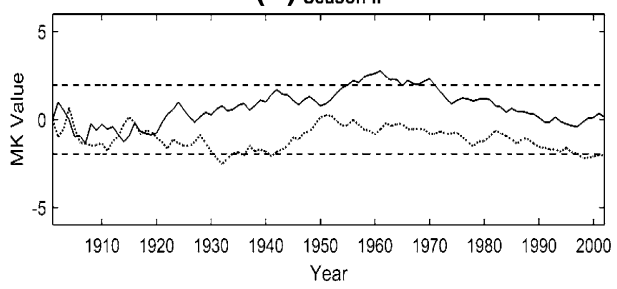

(b) Season II

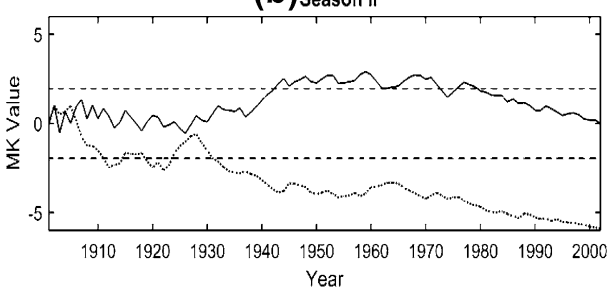

(d) Yearly

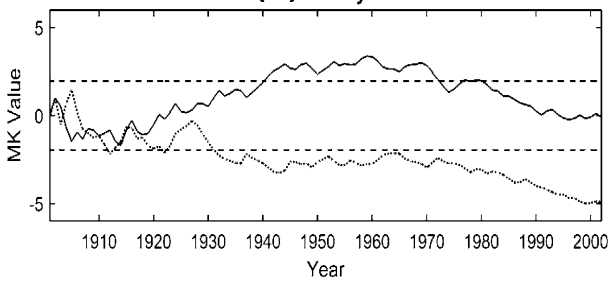

\begin{tabular}{llrrrrr}
\hline Season & r1 & \multicolumn{1}{l}{ ZMK } & Trend & Sen slope & Intercept & Relative change \\
\hline Season I & 0.4478 & -1.9256 & -10 & -0.0042 & 12.6362 & -1.8868 \\
Season II & 0.1968 & 1.1508 & 0 & 0.0016 & 16.6772 & 0.8021 \\
Season III & 0.3167 & -0.3325 & 0 & -0.0004 & 19.7496 & -0.1401 \\
Yearly & 0.4198 & -0.3354 & 0 & -0.0009 & 42.0368 & -0.1280 \\
\hline
\end{tabular}

Fig. 4 Sequential value of statistics $\mathrm{u}(\mathrm{t})(-)$ and $\mathrm{u}^{\prime}(\mathrm{t})(-)$ : seasonal and yearly PET from MK test for Giridih station (a) Season I

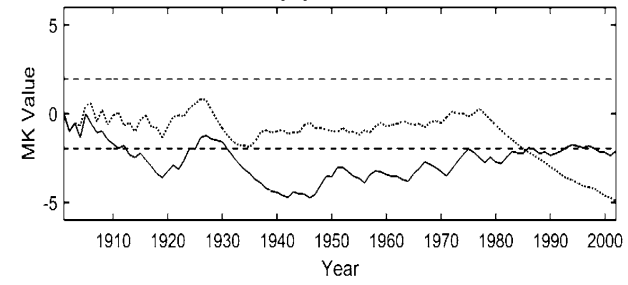

(c) Season III

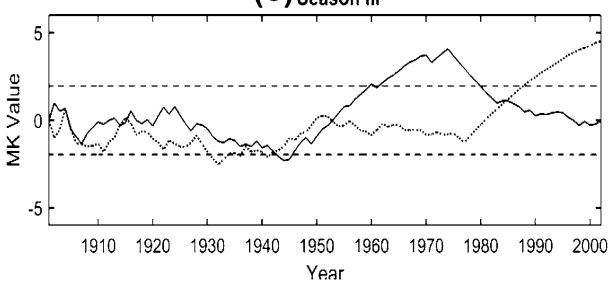

(b) Season II

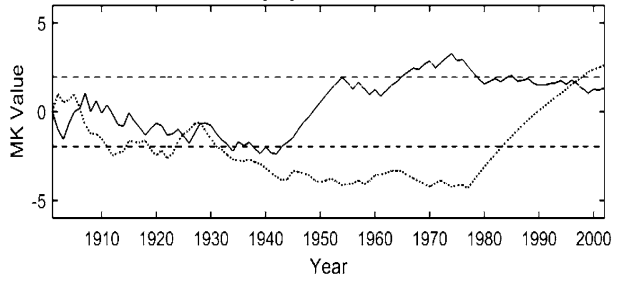

(d) Yearly

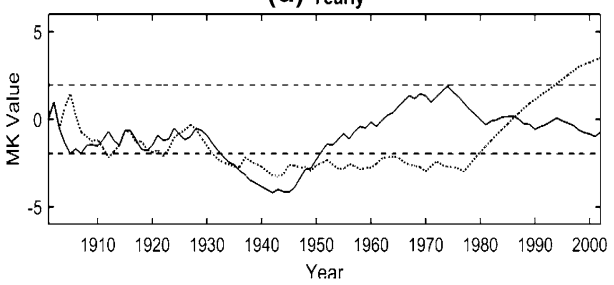

relative change has been presented in Table 4. It can be seen that, for season 1 , station exhibited persistence with significant decreasing trend whereas in season 2, station does not showed any significant persistence and trend. In the case of season 3 station exhibited significant persistence with no trend. The magnitude of trend in seasonal and annual determined by the Sen's estimator has also been shown in Table 4 . It has been observed that decrease in season 1(monsoon) rainfall is $2.042 \mathrm{~mm} /$ year. The decrease in annual rainfall has also been observed as $2.0861 \mathrm{~mm} /$ year. The results of the sequential MK test have been presented in Fig. 5. There was no significant trend detected in rainfall in season 2 and season 3. However in season 1, it was noted that graphical representation begins to diverge in the late 1950s indicating the starting point of the trend. The meaningful long term trends may be identified in decreasing mode started in late 1950s till the rest of period for season 1 . The long term trend of yearly rainfall is identified in decreasing mode beginning in early 1955 s till the rest of period. Decreasing trends in rainfall in season 1 may affect the vegetative phase of rice crop causes low crop production. 
Table 4 Serial correlation analysis and trend analysis for rainfall

\begin{tabular}{lrrcccc}
\hline Season & \multicolumn{1}{c}{ r1 } & \multicolumn{1}{c}{ ZMK } & Trend & Sen slope & Intercept & Relative change \\
\hline Season I & 0.1801 & -2.8509 & -1 & -2.0424 & 981.1785 & -19.1986 \\
Season II & -0.0066 & 1.6249 & 0 & 0.3511 & 83.5493 & 32.9159 \\
Season III & 0.1437 & -1.2838 & 0 & -0.053 & 27.0375 & -20.3286 \\
Yearly & 0.1369 & -2.6658 & -1 & -2.0861 & 1390.368 & -16.3643 \\
\hline
\end{tabular}

Fig. 5 Sequential value of statistics $\mathrm{u}(\mathrm{t})(-)$ and $\mathrm{u}^{\prime}(\mathrm{t})(-)$ : seasonal and yearly rainfall from MK test for Giridih station
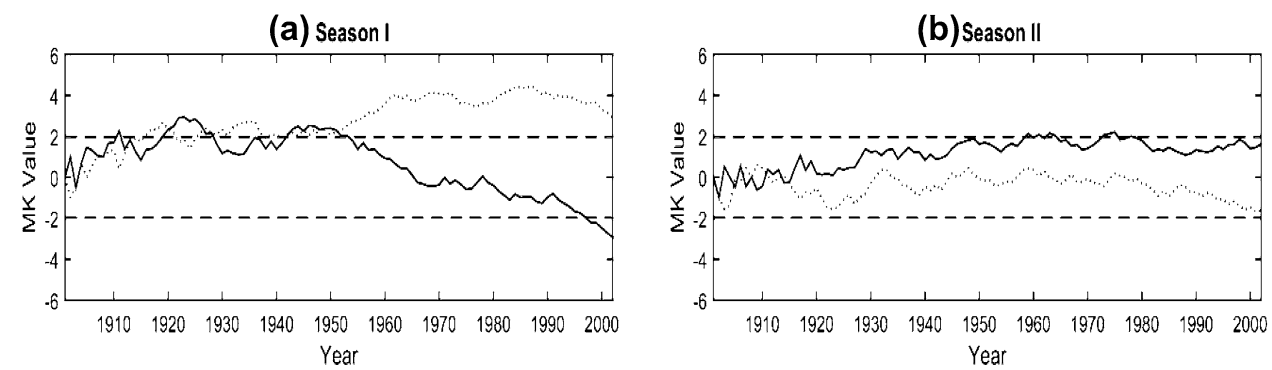

(c) Season III

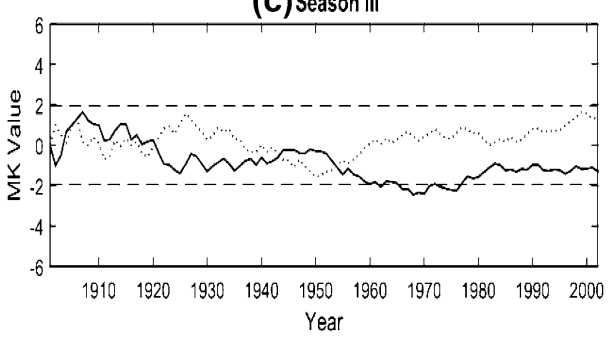

(d) Yearly

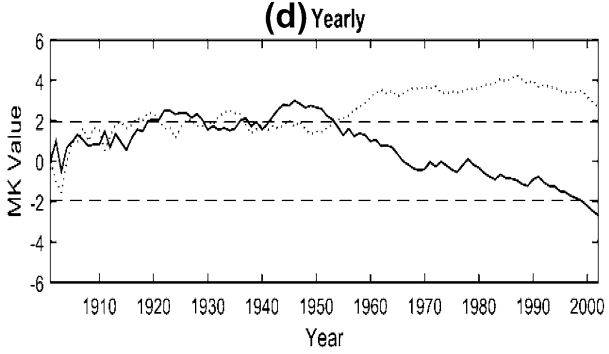

\section{Conclusions}

In this study, trend and persistence analysis of different climatic variables were carried out for Giridih district, Jharkhand (India). An understanding of trends of climatic variables would be provided useful information for the planning, development and management of water in any area or region. The hydrological response of any region depends on several climatic variables, in particular temperature and rainfall. Yearly and seasonal trend analyses for two temperature variables i.e maximum and minimum temperature were analyzed. It was found that there was no significant trend observed in monsoon and summer session for maximum and minimum temperature. Whereas, a significant increasing trend in the region was observed for the winter season. The increase of temperature during winter may hampered the growing stages of water use for winter crop (wheat), which was important for Rabi crop in the most part of this region. Change in temperature affects the relative humidity and evaporation which may affect the crop water demand (Suryavanshi et al. 2014). As far as rainfall is concerned, there was a significant decreasing trend of $2.04 \mathrm{~mm} /$ year observed during the monsoon season (season 1). As rice was important crop grown in May to October in this region, the decreasing trend of rainfall may affect the vegetative phase of rice crop resulting low crop production. Therefore, the irrigation was very much needed in this region to come out with stress situation for future. However, significant persistence was observed in season 1, season 3 and yearly rainfall, and was indicative of the presence of low frequency fluctuation in the rainfall time series. Our recent study also agreed with those of previous studies for Jharkhand state (FAI 2003-2004; Rajeevan et al. 2006; Guhathakurta and Rajeevan 2008; Subash et al. 2011). The long-term trend of monsoon season and yearly rainfall is identified as decreasing mode in late 1950s and early 1955 s respectively till the end.

Acknowledgments The authors would like to thank the SHIATS, Uttar Pradesh (India) for providing the necessary facilities. Acknowledgements are also due to the India water portal and Jharkhand Space Application Centre for making available the datasets used for this study.

\section{References}

Arora M, Goel NK, Singh P (2005) Evaluation of temperature trends over India. Hydrol Sci J 50:81-93

Barnett TP, Adam JC, Lettenmaier DP (2005) Potential impacts of a warming climate on water availability in snow-dominated regions. Nature 438:303-309

Basistha A, Arya DS, Goel NK (2009) Analysis of historical changes in precipitation in the Indian Himalayas. Int $\mathrm{J}$ Climatol 29:555-572 
Burn DH, Hag Elnur MA (2002) Detection of hydrologic trends and variability. J Hydrol 255:107-122

Chen LX, Dong M, Shao YN (1992) The characteristic of international variations on the east Asian Monsoon. J Meteorol Soc Jpn 70:397-421

Dvorak V, Hladny J, Kasparek L (1997) Climate change, hydrology and water resources impact and adoption for selected river basins in Czech Republic. Clim Change 36:93-107

Eckhardt K, Ulbrich U (2003) Potential impacts of climate change on groundwater recharge and streamflow in a central European low mountain range. J Hydrol 284:244-252

Fertiliser Association of India (FAI) (2003-2004) Fertilizer and agriculture statistics, Eastern Region, New Delhi

Gadgil A, Dhorde A (2005) Temperature trends in twentieth century at Pune, India. Atmos Environ 39:6550-6556

Gosain AK, Rao S, Basuray D (2006) Climate change impact assessment on hydrology of Indian River basins. Curr Sci 90:346-353

Guhathakurta P, Rajeevan M (2008) Trends in the rainfall pattern over India. Int J Climatol 28:1453-1469

Hamed KH (2009) Enhancing the effectiveness of prewhitening in trend analysis of hydrologic data. J Hydrol 368:143-155

Hingane LS (1995) Is a signature of socio-economic impact written on the climate? Clim Change 32:91-101

Hirsch RM, Slack JR, Smith RA (1982) Techniques of trend analysis for monthly water quality data. Water Resour Res 18:107-121

IPCC (2007) Summary for policymakers. In: Solomon SD et al (eds) Climate change 2007: the physical science basis. Cambridge University Press, Cambridge

Jain SK, Kumar V (2012) Trend analysis of rainfall and temperature data for India. Curr Sci 102:37-49

Jiang T, Su B, Hartmann H (2007) Temporal and spatial trends of precipitation and river flow in the Yangtze River Basin, 1961-2000. Geomorphol 85:143-154

JSAC/TECH-REP/RD-GOJ/WSMIS-JRD/09-10/07 (2010) prioritization of watershed in Jharkhand state (based on iwmp criteria and satellite derived parameters

Kadioglu M (1997) Trends in surface air temperature data over Turkey. Int J Climatol 17:511-520

Kalra N, Chakraborty D, Sharma A, Rai HK, Jolly M, Chander S, Kumar PR, Bhadraray S, Barman D, Mittal RB, Lal M, Sehgal M (2008) Effect of increasing temperature on yield of some winter crops in northwest India. Curr Sci 94:82-88

Kendall MG (1975) Rank correlation methods. Charles Griffin, London

Khaliq MN, Ouarda TBMJ, Gachon P, Sushama L, St Hilaire A (2009) Identification of hydrologic trends in the presence of serial and cross correlations. A review of selected methods and their application to annual flow regimes of Canadian rivers. J Hydrol 368:117-130

Kishore P, Jyothi S, Basha G, Rao SVB, Rajeevan M, Velicogna I, Sutterley TC (2016) Precipitation climatology over India: validation with observations and reanalysis datasets and spatial trends. Clim Dyn 46:541-556

Kulkarni A, Von Storch H (1995) Monte-Carlo experiments on the effect of serial correlation on the Mann-Kendall test of trend. Meteorol Z 4:82-85

Kundu A, Dwivedi S, Chandra V (2014) Precipitation trend analysis over eastern region of India using CMIP5 based climatic models, The Int Archives Photogram Remote Sens Spatial Info Sci, Volume XL-8, 2014, ISPRS Technical Commission VIII Symposium, 09-12 December 2014, Hyderabad, India

Kundu A, Chatterjee S, Dutta D, Siddiqui AR (2015) Meteorological trend analysis in Western Rajasthan (India) using geographical information system and statistical techniques. J Environ Earth Sci 5:90-99
Lal M (2001) Climatic change Implications for India's water resources. J Indian Water Resour Soc 21:101-119

Lu A, He Y, Zhang Z, Pang H, Gu J (2004) Regional structure of global warming across China during twentieth century. Clim Res 27:189-195

Mann HB (1945) Non-parametric tests against trend. Econom $13: 245-259$

Matalas NC (1967) Time series analysis. Water Resour Res 3:817-829

Nicholson SE, Palao IM (1993) A re-evaluation of rainfall variability in the Sahel, Part I, Characteristics of rainfall fluctuations. Int J Climatol 13:371-389

Pant GB, Kumar KR (1997) Climates of South Asia. Wiley, West Sussex

Partal T, Kahya E (2006) Trend analysis in Turkish precipitation data. Hydrol Process 20:2011-2026

Rajeevan M, Bhate J, Kale JD, Lal B (2006) High resolution daily gridded rainfall data for the Indian region: analysis of break and active monsoon spells. Curr Sci 91:296-306

Rao GP, Kumar KK (1992) Climatic shifts over Mahanadi river basin in India. Clim Res 2:215-223

Reeves J, Chen J, Wang XL, Lund R, QiQi L (2007) A review and comparison of changepoint detection techniques for climate data. J Appl Meteorol Climatol. doi:10.1175/JAM2493.1

Rodhe H, Virji H (1976) Trends and periodicities in East African rainfall data. Mon Weather Rev 104:307-315

Rupakumar K, Hingane LS (1988) Long -term variations of Surface air temperature at major industrial cities of India. Clim Change 13:287-307

Sadhukhan I, Lohar D, Pal DK (2000) Pre-Monsoon season rainfall variability over Gangetic West Bengal and its neighborhood, India. Int J Climatol 20(12):1485-1493

Sen PK (1968) Estimates of the regression coefficient based on Kendall's tau. J Am Stat Assoc 63:1379-1389

Singh P, Kumar V, Thomas T, Arora M (2008) Changes in rainfall and relative humidity in different river basins in the northwest and central India. Hydrol Process 22:2982-2992

Sneyers R (1990) On the statistical analysis of series of observations. World Meteorological Organization, Technical Note 143, Geneva, Switzerland

Some'e BS, Ezani A, Tabari H (2012) Spatiotemporal trends and change point of precipitation in Iran. Atmos Res 113:1-12

Sonali P, Kumar N (2013) Review of trend detection methods and their application to detect extreme temperature changes in India. J Hydrol 476:212-227

Subash N, Sikka AK, Ram Mohan HS (2011) An investigation into observational characteristics of rainfall and temperature in Central Northeast India-a historical perspective 1889-2008. Theor Appl Climatol 103:305-319

Suryavanshi S, Panday A, Chaube UC, Joshi N (2014) Long term historic changes in climatic variables of Betla Basin, India. Theor Appl Climatol 117:403-418

Theil H (1950a) A rank invariant method of linear and polynomial regression analysis, Part 3. Neth Akad van Wettenschappen Proc 53:1397-1412

Theil H (1950b) A rank-invariant method of linear and polynomial regression analysis, I. Ned Akad Wetensch Proc 53:386-392

Theil H (1950c) A rank-invariant method of linear and polynomial regression analysis, II. Ned Akad Wetensch Proc 53:521-525

Theil H (1950d) A rank-invariant method of linear and polynomial regression analysis, III. Ned Akad Wetensch Proc 53:1397-1412

Tomozeiu R, Pavan V, Cacciamani C, Amici M (2006) Observed temperature changes in Emilia-Romagna: mean values and extremes. Clim Res 31:217-225 
Türkes M, Sümer UM, Kiliç G (2002) Persistence and periodicity in the precipitation series of Turkey and associations with $500 \mathrm{hPa}$ geopotential heights. Clim Res 21:59-81

WMO (1966) Climatic change. WMO Technical Note 79, World Meteorological Organization, Geneva
Yevjevich V (1971) Stochastic processes in hydrology. Water Resources Publications, Fort Collins, Colorado, USA

Yue S, Pilon P, Cavadias G (2002) Power of the Mann-Kendall and Spearman's rho test for detecting monotonic trends in hydrological series. J Hydrol 259:254-271 